\title{
Constitutive activation of an epithelial signal transducer and activator of transcription (STAT) pathway in asthma
}

\author{
Deepak Sampath, ${ }^{1}$ Mario Castro, ${ }^{1}$ Dwight C. Look, ${ }^{1}$ and Michael J. Holtzman ${ }^{1,2}$ \\ ${ }^{1}$ Department of Medicine, and \\ ${ }^{2}$ Department of Cell Biology, Washington University School of Medicine, St. Louis, Missouri 63110, USA
}

Address correspondence to: M.J. Holtzman, Washington University School of Medicine, Campus Box 8052, 660 South Euclid Avenue, St. Louis, Missouri 63110, USA. Phone: (314) 362-8970; Fax: (314) 362-8987; E-mail: mholtzman@pulmonary.wustl.edu

Received for publication December 22, 1998, and accepted in revised form March 23, 1999.

\begin{abstract}
Cytokine effects on immunity and inflammation often depend on the transcription factors termed signal transducers and activators of transcription (STATs), so STAT signaling pathways are candidates for influencing inflammatory disease. We reasoned that selective IFN responsiveness of the first STAT family member (Stat1) and Stat1-dependent immune-response genes such as intercellular adhesion molecule-1 (ICAM-1), IFN regulatory factor-1 (IRF-1), and Stat 1 itself in airway epithelial cells provides a basis for detecting cytokine signaling abnormalities in inflammatory airway disease. On the basis of nuclear localization and phosphorylation, we found that epithelial Stat1 (but not other control transcription factors) was invariably activated in asthmatic compared with normal control or chronic bronchitis subjects. Furthermore, epithelial levels of activated Stat 1 correlated with levels of expression for epithelial ICAM-1, IRF-1, and Stat1, and in turn, ICAM-1 levels correlated with T-cell accumulation in tissue. However, only low levels of IFN- $\gamma$ or IFN- $\gamma$-producing cells were detected in airway tissue in all subjects. The results therefore provide initial evidence linking abnormal behavior of STAT pathways for cytokine signaling to the development of an inflammatory disease. In that context, the results also change the current scheme for asthma pathogenesis to one that must include a localized gain in transcriptional signal ordinarily used for a T helper 1-type cytokine (IFN- $\gamma$ ) in combination with allergydriven overproduction of T helper 2-type cytokines.
\end{abstract}

J. Clin. Invest. 103:1353-1361 (1999).

\section{Introduction}

Cytokines are critical for regulating immunity and inflammation, so it is not surprising that altered cytokine production has been implicated in causing inflammatory diseases. However, cytokines depend on signal transduction pathways to transmit their specific effects, so it is also possible that even normal levels of cytokines coupled to an abnormal signaling pathway could lead to an aberrant response and consequent inflammation. Although many cytokines depend on a family of signaling molecules designated signal transducers and activators of transcription (STATs) to mediate specific responses, the behavior of STAT proteins during the abnormal immune cell responses that characterize inflammatory diseases remain uncertain $(1,2)$.

In this context, asthma is one of the most common immune disorders and has been characterized as an inflammatory airway disease with eosinophil influx and a predisposition to allergic reactions (3-7). By analogy to murine immunology, the disease has been further categorized as manifesting an aberrant immune response biased toward production of T-helper 2 (Th2) cytokines such as IL-4 and IL-5 and away from T-helper 1 (Th1) cytokines such as IFN- $\gamma(8-11)$. Because not all patients with asthma have an identifiable allergic trigger for their disease, we have questioned the "Th2 diathesis" as a sole explanation for asthma and have suggested a role for other aspects of airway immunity $(12,13)$. We have provided evidence for the role of epithelial immune-response genes in mucosal immunity and the possibility that abnormal regulation of these genes may lead to airway inflammation (14). This alternative features an IFN- $\gamma$-responsive signaling pathway that relies on the dual ability of the initial member of the STAT family (Stat1) to first be phosphorylated and dimerized by the IFN- $\gamma$-receptor complex and then to translocate to the nucleus and selectively transactivate genes containing a Stat 1 binding site $(1,2)$. In airway epithelial cells, this Stat1-dependent pathway is thereby programmed for IFN- $\boldsymbol{\gamma}$-inducible expression of a subset of immune-response target genes typified by intercellular adhesion molecule-1 (ICAM-1) (15-18). Distribution of ICAM- 1 along the epithelial cell surface is then positioned to mediate epithelial T-cell interaction, including cell-cell adhesion and antigen presentation $(14,19,20)$, whereas concomitant expression of other subset members such as IFN regulatory factor 1 (IRF-1) coordinate other aspects of mucosal immunity relevant to antiviral defense $(18,21)$.

In the present study, we aimed to extend our findings on epithelial cell behavior to studies of human subjects, taking advantage of the capacity for Stat 1 and a subset of Stat1-dependent genes to respond selectively to IFN- $\gamma$ in this cell type $(15-19,22,23)$. We demonstrate that bronchial epithelial Stat 1 is activated in concert with expression of its target genes in stable asthma, but not in normal controls or in subjects with airway inflammation due to chronic bronchitis. Because tissue levels of IFN- $\gamma$ 
Table 1

Characteristics of subjects

$\begin{array}{lccc}\text { Characteristic } & \begin{array}{c}\text { Normal control } \\ \text { subjects } \\ (n=11)\end{array} & \begin{array}{c}\text { Asthma } \\ \text { subjects } \\ (n=24)\end{array} & \begin{array}{c}\text { Chronic bronchitis } \\ \text { subjects } \\ (n=8)\end{array} \\ \text { Age (years) } & 32 & 36 & 67 \\ \text { Mean } & 20-54 & 20-64 & 42-76 \\ \text { Range } & 7 / 4 & 10 / 14 & 3 / 5 \\ \text { Gender (male/female) } & 4 & 22 & \mathrm{ND}^{\mathrm{C}} \\ \text { Atopy } & 0 & 2 & 2 \\ \text { Glucocorticoid treatment } & 4.25 \pm 0.78 & 2.64 \pm 1.07 & 1.24 \pm 0.74 \\ \text { FEV1A (L/min) } \pm \text { SD } & 106 \pm 13 & 80 \pm 28 & 51 \pm 10 \\ \text { Percent predicted } \pm \text { SD } & 81-129 & 27-114 & 41-69 \\ \text { Range of percent predicted } & >16 & 1.21 \pm 2.06 & \mathrm{ND}^{\mathrm{C}} \\ \text { FEV1 PC20B }(\mathrm{mg} / \mathrm{mL}) \pm \mathrm{SD} & >16 & 0.025-7.5 & \mathrm{ND}^{\mathrm{C}} \\ \text { range } & & & \end{array}$

ADenotes forced expiratory volume in 1 second.

${ }^{B}$ Denotes provocative concentration of methacholine required to cause a $20 \%$ decrease in baseline FEV1.

cNot determined.

are not increased, asthma appears to be characterized by constitutive activity of Th1-like cytokine signaling, even without evidence of stimuli, such as IFN- $\gamma$ or viral infection $(24,25)$, that normally drive this type of immune reaction.

\section{Methods}

Study subjects. Eleven healthy control, 24 asthma, and 8 chronic bronchitis subjects were recruited, using informed consent for a protocol approved by the University Committee for Human Studies, and were characterized by spirometry, airway reactivity to inhaled methacholine, and skin test reactivity - as summarized in Table 1. Control subjects had no clinical history of airway obstruction and had normal spirometry and normal airway reactivity. Asthmatic subjects met clinical diagnostic criteria for asthma (26) and showed hyperreactivity to inhaled methacholine. Two of the asthmatic subjects were being treated with inhaled glucocorticoids at the time of study. Positive skin test reactivity to a panel of allergens (house dust, trees, grasses, fungi, cockroach, and dog and cat dander) was observed in 22 of the asthmatic subjects and 4 of the control subjects. Chronic bronchitis subjects met clinical diagnostic criteria for chronic bronchitis (26) and had airflow obstruction. For all subjects, there was no history of endotracheal intubation within the past 5 years, respiratory tract infection within the past 3 months, or significant cardiac or neurologic disease.

Procurement and processing of cells and tissue. Endobronchial biopsies and brushings were obtained from all subjects using a fiberoptic bronchoscope. For each subject, 6-8 endobronchial biopsies of proximal airway tissue were obtained from undisturbed areas using a 2-mm forceps, and endobronchial brushings were obtained from 10 separate airway segments using a cytology brush. Endobronchial biopsies were either frozen in Tissue-Tek OCT (Sakura Finetek, Torrance, California, USA) and TBS Tissue Freezing Medium (Triangular Biomedical Science Durham, North Carolina, USA) or fixed in 10\% neutralbuffered formalin and embedded in paraffin. Endobronchial brushings were collected in ice-cold serum-free RPMI-1640 media containing amphotericin B, penicillin/streptomycin, and L-glutamine; they were then washed with cold PBS and subjected to hypotonic lysis to eliminate red blood cells. Brushings obtained in this manner contained cells that were $50-80 \%$ viable by trypan blue exclusion. Airway epithelial cells from all subjects comprised $>95 \%$ of brushed cells, based on morphology and immunostaining with anti-cytokeratin $\mathrm{mAb}$. An aliquot of the cells was subjected to cytocentrifugation onto glass slides fol- lowed by fixation with acetone/methanol for 5 minutes at $25^{\circ} \mathrm{C}$, and slides were air dried and stored at $-20^{\circ} \mathrm{C}$ for subsequent immunostaining. The remaining portion of brushed cells was lysed in $100 \mu \mathrm{L}$ of Tris- $\mathrm{HCl}(\mathrm{pH} 8.0)$ containing $10 \% \mathrm{NP}-40,1 \%$ Triton X-100, and $0.1 \%$ SDS, and lysates were stored at $-20^{\circ} \mathrm{C}$ for immunoblotting. In some subjects, bronchoalveolar lavage (with five $20-\mathrm{mL}$ aliquots of $0.9 \% \mathrm{NaCl}$ ) was also performed, and the fluid was used to isolate macrophages ( $>95 \%$ purity and viability) by differential adherence as described previously (27). Lysates of bronchoalveolar macrophages and primary-culture human tracheobronchial epithelial cells $(14-20,22)$ were also immunoblotted for comparison to brushed epithelial cells.

Immunomicroscopy. Cytospin preparations of epithelial cell brushings were treated with $2 \%$ gelatin to block nonspecific Ig binding and were then incubated with anti-Stat1 $\mathrm{mAb}(12$ $\mu \mathrm{g} / \mathrm{mL}$; Transduction Laboratories, Lexington, Kentucky, USA), anti-cytokeratin mAb (1 $\mathrm{g} / \mathrm{mL}$; Sigma Chemical Co., St. Louis, Missouri, USA), or nonimmune isotype-matched mouse IgG for 18 hours at $4{ }^{\circ} \mathrm{C}$. Primary Ab binding was detected with TRITC-conjugated donkey anti-mouse IgG Ab $(5 \mu \mathrm{g} / \mathrm{mL}$; The Jackson Laboratory, Bar Harbor, Maine, USA). Stat1 nuclear translocation was detected by colocalization with bisbenzimide (HOECHST) and was quantified by assessing 250 cytokeratinimmunopositive cells for each subject.

Frozen endobronchial biopsies were cut into $6-\mu \mathrm{m}$ sections that were washed in Tris-buffered saline, blocked by treatment with $2 \%$ gelatin, and incubated with anti-Stat $1 \mathrm{mAb}(12$ $\mu \mathrm{g} / \mathrm{mL})$, anti-ICAM-1 mAb 84H10 $(1 \mu \mathrm{g} / \mathrm{mL}$; Immunotech, Westbrook, Maine, USA), anti-p65 (RelA) subunit of nuclear factor- $\mathrm{KB}(\mathrm{NF}-\mathrm{\kappa B}) \mathrm{pAb}(2 \mu \mathrm{g} / \mathrm{mL})$, or anti-c-fos subunit of activator protein 1 (AP-1) pAb $(2 \mu \mathrm{g} / \mathrm{mL}$; Santa Cruz Biotechnology Inc., Santa Cruz, California, USA) for 18 hours at $4^{\circ} \mathrm{C}$. As a positive control for Stat1, NF-KB, or AP-1 activation, some biopsy samples were also stimulated for 24 hours with IFN- $\gamma$ $(100 \mathrm{U} / \mathrm{mL})$, TNF- $\alpha(100 \mathrm{U} / \mathrm{mL})$, or PMA $(10 \mathrm{ng} / \mathrm{mL})$, respectively. Primary Ab binding was detected with FITC- or TRITCconjugated donkey anti-mouse IgG Ab and then viewed by scanning laser confocal microscopy with images generated at $\times 600$ using a computer interface as described previously (14). Stat 1 translocation was quantified by analyzing a $1-\mathrm{mm}^{2}$ field of epithelium in each biopsy section.

Formalin-fixed biopsies were also cut into $6-\mu \mathrm{m}$ sections. Tissue sections were deparaffinized and rehydrated with graded ethanol solutions, and endogenous peroxidase activity was blocked by treatment with $3 \%$ hydrogen peroxide for 30 minutes at $25^{\circ} \mathrm{C}$. Antigen exposure was facilitated by an antigen-retrieval method in which tissue specimens were placed in $10 \mathrm{mM}$ Citra solution (BioGenex Laboratories, San Ramon, California, USA) for 10 minutes at $98^{\circ} \mathrm{C}$. After tissue specimens cooled to $25^{\circ} \mathrm{C}$, nonspecific antigens were blocked by exposure to $3 \%$ nonimmune horse serum for 30 minutes at $25^{\circ} \mathrm{C}$. Slides were then incubated with anti-Stat 1 and anti-ICAM-1 mAb as already described here, and with antiCD3 mAb $(1 \mu \mathrm{g} / \mathrm{mL})$ from BioGenex. Primary Ab binding was detected with biotinylated horse anti-mouse IgG Ab, streptavidin-conjugated alkaline phosphatase, and red chromogenic substrate (Vector Laboratories, Burlingame, California, USA). Tissue sections were counterstained with hematoxylin, dehydrated in graded ethanol, and mounted for viewing and photomicrography. To quantitate immunostaining, images were acquired using the Pax It computer program (Midwest Information Systems, Franklin Park, Illinois, USA) and transferred to an image analysis program (Optimus, Seattle, Washington, USA) set to calculate red intensity of a square of airway epithelium $(50 \times 50 \mathrm{~mm})$ relative to the same-sized square of subepithelium using an RGB scale. Red intensity was calculated for 5 squares of epithelium and averaged to obtain a value for each biopsy. 

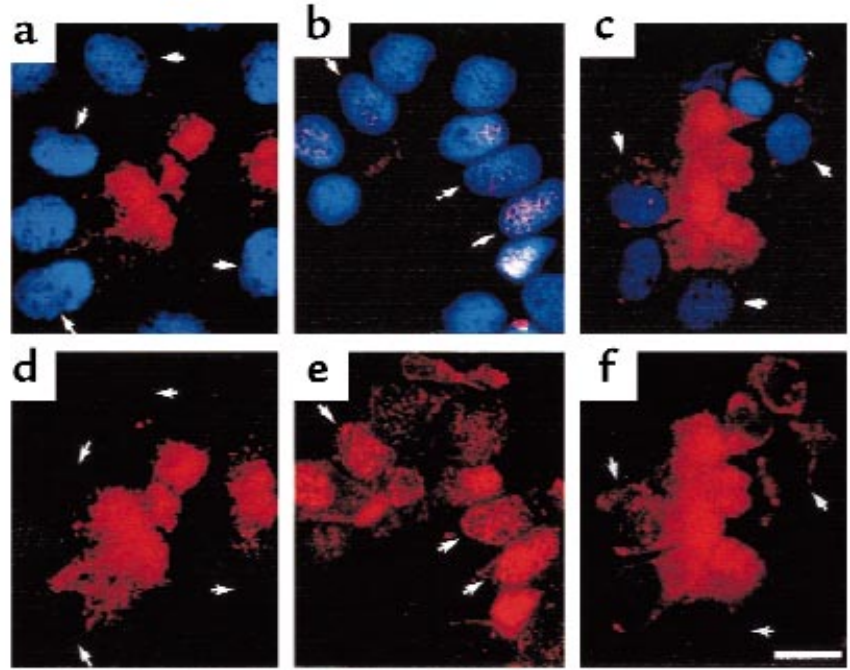
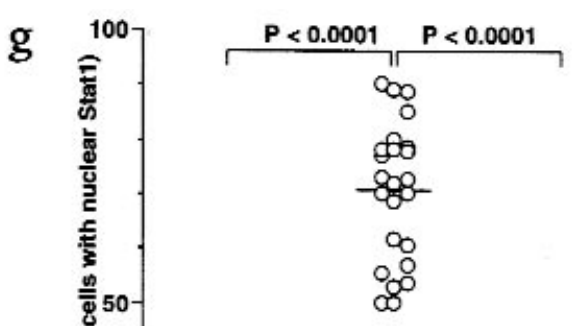

○

○

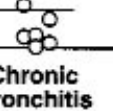

Figure 1

Stat 1 activation in asthma detected by nuclear translocation in airway epithelial cells. (a-f) Representative immunofluorescence photomicrographs of bronchial epithelial cells brushed from control ( $\mathbf{a}$ and $\mathbf{d}$ ), asthma ( $\mathbf{b}$ and $\mathbf{e}$ ), and chronic bronchitis (c and $\mathbf{f}$ ) subjects; immunostained with antiStat1 Ab plus TRITC-conjugated secondary Ab; and then counterstained with bisbenzimide to localize cell nuclei (indicated by arrowheads). (a-c) Stat1 plus bisbenzimide signals (red plus blue fluorescence). (d-f) Stat1 signal (red fluorescence). Control staining with nonimmune IgG gave no detectable signal above background (not shown). (g) Quantitative analysis of Stat1 nuclear translocation for all subjects. Values were derived by calculating the percentage of cells in which Stat 1 colocalized with bisbenzimide out of 250 cytokeratin-staining cells per subject. Scale bar: $15 \mu \mathrm{M}$.

Immunoprecipitation and immunoblot analysis. Immunoprecipitation and immunoblotting for Stat 1 phosphorylation and for Stat 1 and IRF-1 expression were performed as described previously (16-18). Briefly, whole cell lysates were prepared in $0.1 \%$ NP-40, $1.0 \%$ Triton X-100, and $0.1 \%$ SDS buffers containing protease inhibitors, and the lysates $(100 \mu \mathrm{g} /$ condition $)$ were immunoprecipitated with agarose-conjugated anti-Stat $1 \mathrm{pAb}$ $(20 \mu \mathrm{l})$ from Santa Cruz Biotechnology Inc. The immune complex was subjected to SDS-PAGE using an $8 \%$ polyacrylamide gel and transferred onto polyvinylidene difluoride (PVDF) membranes that were probed with $1 \mu \mathrm{g} / \mathrm{mL}$ of anti-phosphotyrosine $\mathrm{mAb}$ conjugated to horseradish peroxidase (PY20-H) from Transduction Laboratories. Binding was detected by an enhanced chemiluminescence method (Amersham International, Amersham, United Kingdom). PVDF membranes were reprobed with anti-Stat $1 \mathrm{mAb}(1 \mu \mathrm{g} / \mathrm{mL})$ to confirm the identity of phosphorylated Stat 1 . In addition, levels of Stat 1 and IRF1 were determined by immunoblotting lysates (without prior immunoprecipitation) using anti-Stat $1 \mathrm{mAb}(1 \mu \mathrm{g} / \mathrm{mL})$, antiIRF-1 pAb $(1 \mu \mathrm{g} / \mathrm{mL}$; Santa Cruz Biotechnology Inc.), and (as a control) anti- $\beta$-actin $\mathrm{mAb}(0.5 \mu \mathrm{g} / \mathrm{mL}$; Sigma Chemical Co. $)$.

In situ bybridization. For IFN- $\gamma$ riboprobe synthesis, a $0.9-\mathrm{kb}$ human cDNA fragment (nt 1-900) was positionally cloned into the EcoRI and HindIII sites of pGEM3Zf-1 (Promega Corp., Madison, Wisconsin, USA) to generate pGEM3Zf-1IFN- $\gamma(1-900)$. Radiolabeled ${ }^{35}$ S-UTP sense and antisense cRNA transcripts were transcribed in vitro by T3 and T7 RNA polymerases, respectively, using the Gemini Riboprobe system (Promega Corp.). In situ hybridization was performed as described previously (14), using biopsy tissue that was either unstimulated or stimulated with PMA $(10 \mathrm{ng} / \mathrm{mL})$ and ionomycin $(500 \mathrm{ng} / \mathrm{mL})$ for 5 hours at $37^{\circ} \mathrm{C}$.

RT-PCR. Airway tissue levels of IFN- $\gamma$ mRNA were quantified using RT-PCR with primers specific for IFN- $\gamma$, IL-4 (positive control), and $\beta$-actin (internal standard). Total RNA was isolated as described previously (22) from tissue homogenates of 3-4 endobronchial biopsies per subject and from PMA/ionomycin-stimulated PBMCs (positive control). An aliquot of RNA $(5 \mu \mathrm{g})$ was reverse transcribed with the Ready-To-Go kit
(Promega Corp.), and cDNA was amplified in the presence

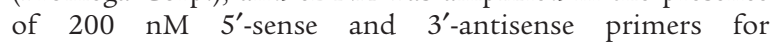
IFN- $\gamma$ (ATGAAATATACAAGTTATATCTTGG-CTTT and GATGCTCTTCGACCTCGAAGCAT), IL-4 (ATGGGTCTCACCTCCCAACTGCT and CGAACACTTTGAATATTTCTCTCTCAT), or $\beta$-actin (TGACGGGGTCACCCACACTGTGCCCATCTA and CTAGAAGCATTGCGGTGGACGATGGA-GGG), $200 \mu \mathrm{M}$ dNTPs, and $0.5 \mathrm{U}$ Taq polymerase (GIBCO BRL, Gaithersburg, Maryland, USA) in $10 \mathrm{mM}$ Tris-Cl ( $\mathrm{pH}$ 8.3) with $2.5 \mu \mathrm{M} \mathrm{MgCl}_{2}, 50 \mathrm{mM} \mathrm{KCl}$, and $0.001 \%$ gelatin. PCR was performed for 40 cycles with a 45 -second denaturation at $95^{\circ} \mathrm{C}$, 45 second annealing at $55^{\circ} \mathrm{C}$, and 45 -second extension at $72^{\circ} \mathrm{C}$ for IFN- $\gamma$ and $\beta$-actin; and for 40 cycles with 45 -second denaturation at $95^{\circ} \mathrm{C}, 45$-second annealing at $60^{\circ} \mathrm{C}$, and 1.5 -minute extension at $72^{\circ} \mathrm{C}$ for IL-4. The reaction products were detected by agarose gel electrophoresis in ethidium bromide and migrated at appropriate sizes for IFN- $\gamma(501 \mathrm{bp})$, IL-4 (456 bp), and $\beta$ $\operatorname{actin}(605 \mathrm{bp})$. Amplified IFN- $\gamma$ cDNA products that were undetectable by ethidium bromide staining were transferred (along with $\beta$-actin) to nylon membranes by capillary electrophoresis, and membranes were hybridized with ${ }^{32} \mathrm{P}$-labeled cDNAs for IFN- $\gamma$ (GACCATCAAGGAAGACATGAATGTCAAGTT) or $\beta$-actin (GGCTGGCCCCGACCTGACTGACTAC-CTCAT). This was followed by autoradiography.

Statistical analysis. Data for immunostaining and in situ hybridization were analyzed using SAS statistical software (SAS Inc., Cary, North Carolina, USA). When data were available in only 2 groups, $t$ tests were used to make comparisons. When data were available in all 3 groups, ANOVA was used to perform pairwise comparisons. When the data were not normally distributed, or if the equal variance assumption of the ANOVA was violated, the data were transformed before performing the analysis. The square root transformation was applied to Stat 1 activation to stabilize the variance; the analysis of CD3 was applied to the ranks of the original data; and percent FEV1 predicted and ICAM-1 expression were analyzed using the square root of the ranks of the data. A $P$ value of less than 0.05 was considered to indicate statistical significance. All results are presented as mean \pm SD. 


\section{Figure 2}

Stat 1 activation and colocalization with ICAM-1 expression in asthma detected in airway epithelial tissue. Representative photomicrographs from scanning laser confocal microscopy of endobronchial biopsy sections from normal control (a, $\mathbf{d}, \mathbf{g}$, and $\mathbf{j}$ ) and asthma (b, e, $\mathbf{h}$, and $\mathbf{k}$ ) subjects, and from normal control subjects after biopsy stimulation ex vivo with IFN- $\gamma$ (c and $\mathbf{f}$ ), TNF- $\alpha$ (i), or PMA (I). Tissues were immunostained with antiStat1 Ab (a-c), anti-ICAM-1 mAb (d-f), anti-p65 (component of NF-KB) pAb ( $\mathbf{g}-\mathbf{i})$, or anti-c-fos (component of AP-1) PAb (j-I). Primary Ab binding was detected with TRITC- or FITC-conjugated secondary $A b$ and viewed with confocal microscopy scanned in $1-\mu \mathrm{M}$ steps along the $z$ axis. No fluorescence was detected for monolayers stained with nonimmune IgG or with only anti-mouse $\operatorname{lgG}$ (not shown). Scale bar: $15 \mu \mathrm{M}$.
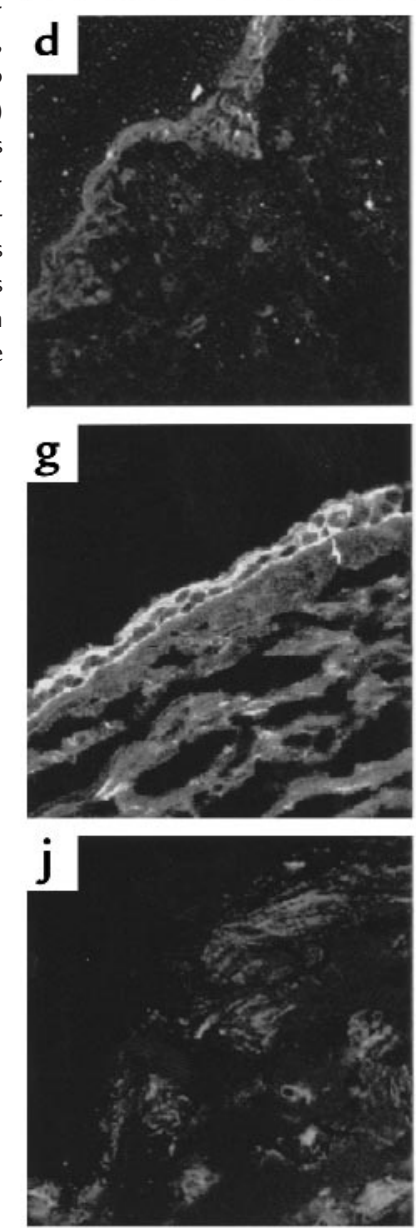
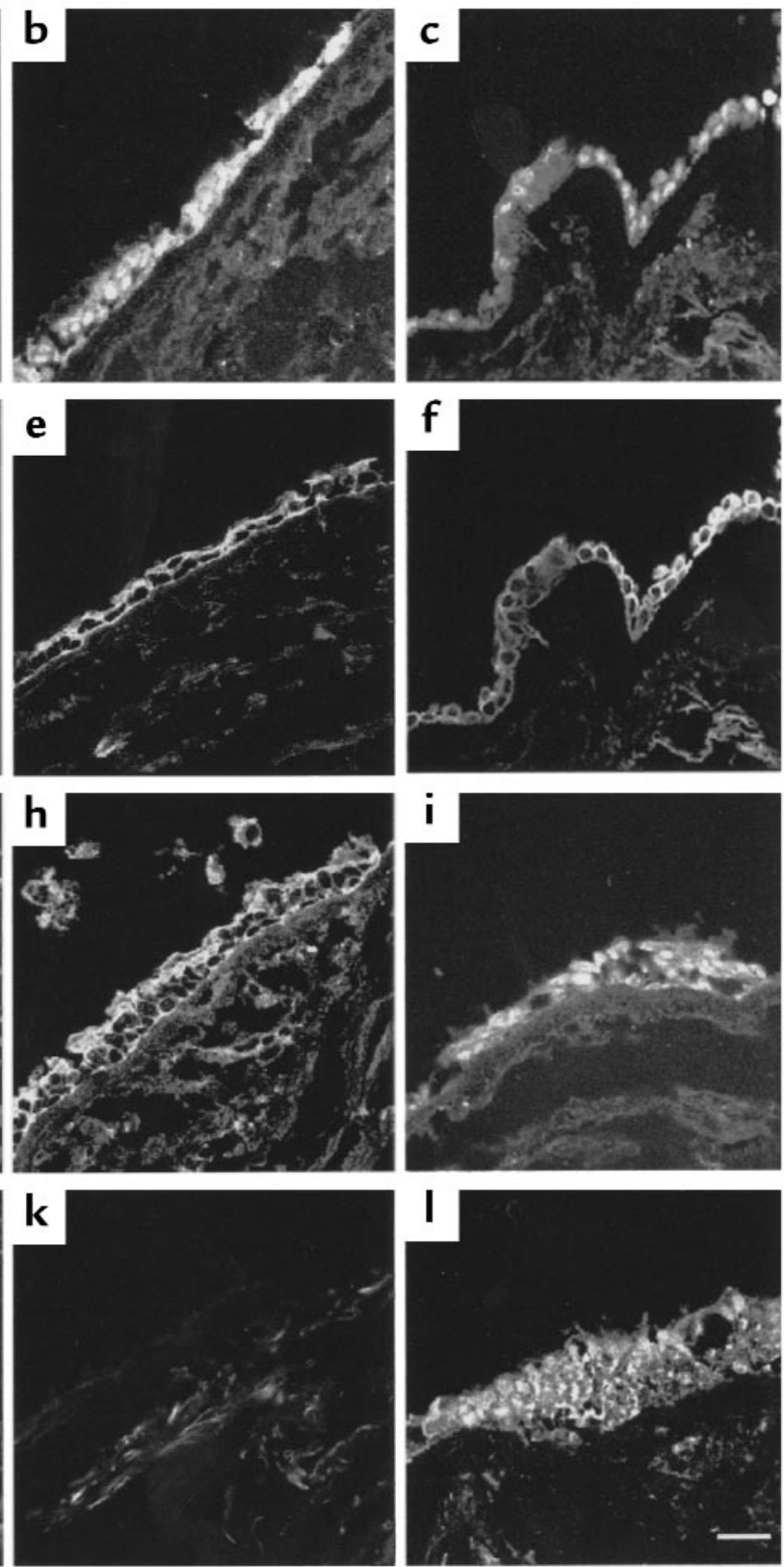

\section{Results}

Selective activation of epithelial Stat1 in asthma. Based on data in isolated airway epithelial cells, nuclear localization appears to represent an accurate indicator of Stat 1 activation and Stat1-dependent gene transcription (16-18). Accordingly, our first analysis of Stat 1 activation status in vivo was based on nuclear localization in bronchial epithelial cells brushed from subjects with and without airway disease. Stat 1 was localized to the nucleus (along with the DNA-binding dye bisbenzimide) in $70 \pm 15 \%$ of cytokeratin-immunopositive bronchial epithelial cells brushed from asthmatic subjects, but in only $11 \pm 11 \%$ of cells from normal controls and $8 \pm 8 \%$ from chronic bronchitis subjects (Figure 1). Activation levels of epithelial Stat1 were increased in asthmatic subjects irrespective of atopy or glucocorticoid treatment, although a larger sample size is required to conclude that Stat 1 activation is not related to these variables. As an additional control, we found no evidence in any of these subjects of activation of epithelial Stat3, a related STAT protein that is responsive to IL-6 and IL-6-related cytokines (28) (data not shown).

Evidence of Stat 1 activation, based on nuclear translocation in endobronchial brushings, was corroborated in situ using endobronchial biopsies. In this case, immunofluorescent confocal microscopy indicated that Stat 1 localized to the nucleus in $4 \pm 1 \%$ of cells in biopsies from 5 control subjects but was detected in $78 \pm 9 \%$ of cells from 5 asthmatic subjects. In fact, cytosolic versus nuclear patterns for Stat 1 correlated precisely with the absence or presence of ICAM-1 expression on a cell-bycell basis within a biopsy (Figure 2, a-f). Selective activation of Stat 1 was further demonstrated when we found that other transcription factors (i.e., NF- $\kappa \mathrm{B}$ and AP-1) implicated in the control of immunity and inflamma- 
tion, as well as asthma exacerbations and subgroups (29-31), were not consistently activated in airway epithelial cells of these stable asthmatic subjects. In particular, subjects with activation of epithelial Stat1, but not NF$\kappa \mathrm{B}$ or AP-1, still exhibit ICAM-1 expression (Figure 2, $\mathrm{g}-1)$. Each of these findings (together with data in airway epithelial cells and Stat1-deficient cell lines showing that Stat 1 activation is sufficient for ICAM- 1 gene transcription and expression) (15-18) indicates that Stat1 activation is likely linked to Stat1-dependent expression of its target gene (ICAM-1) in these subjects.

Evidence of Stat 1 activation, based on nuclear localization in epithelial cells from bronchial brushings and biopsies, was complemented by assessment of Stat 1 phosphorylation status. For these experiments, Stat 1 immunoprecipitation and Western blotting indicated that Stat 1 phosphorylation was detected only in airway epithelial cells brushed from asthmatic subjects (Figure 3 , $a$ and $b$ ). The ratio of phosphorylated to unphosphorylated Stat 1 was increased 20 -fold in extracts of bronchial epithelial cells from asthmatic subjects when compared with normal control or chronic bronchitis subjects (Figure $3 \mathrm{c}$ ). In addition, we found that Stat 1 activation was selective for airway epithelial cells, as bronchoalveolar macrophages from the same subjects showed no evidence of Stat 1 activation or overexpression (Figure 3, $\mathrm{d}$ and e). This analysis provided initial evidence that Stat 1 activation appeared to be accompanied by increased Stat 1 expression (based on the intensity of Stat 1 immunoblotting), and, as noted below, this finding was confirmed with additional immunoblotting and immunostaining for epithelial Stat 1 .

Expression of Stat1-dependent genes in asthma. To determine the functional relevance of Stat 1 activation in asthma, we next assessed the level of expression of ICAM-1, IRF-1, and Stat1 in airway epithelium. Induction of ICAM-1, IRF-1, and Stat 1 expression depends on Stat 1 activation in isolated airway epithelial cells $(15-18,23)$ and in endobronchial biopsies stimulated ex vivo (data not shown), so we reasoned that Stat 1 activation should drive increased expression of ICAM-1, IRF-1, and Stat 1 in vivo. In fact, immunoblotting indicated a marked increase in IRF-1 and Stat 1 levels in brushed airway epithelial cells (Figure $3, \mathrm{f}-\mathrm{h}$ ), and immunostaining indicated a marked increase in expression of epithelial ICAM-1 and Stat 1 in asthmatic subjects compared with normal control or chronic bronchitis subjects (Figure 4). Furthermore, the level of Stat 1 activation correlated closely with the levels of ICAM1 and Stat 1 expression for all 3 groups of subjects (Figure 4 ), as well as within the group of asthmatic subjects (for ICAM-1: $r=0.51$ and $P=0.01$; for Stat $1: r=0.42$ and $P=$ 0.04). In turn, the levels of ICAM-1 expression correlated significantly with the numbers of $\mathrm{T}$ cells found in endobronchial biopsies by CD3 immunostaining (for all subjects, $r=0.57$ and $P=0.004$; for individual examples, see Figure 5 , $a$ and $b$ ). Taken together with data for the behavior of human airway epithelial cells, the findings strongly suggest that activation of epithelial Stat 1 in asthma was linked to consequent induction of its target genes (ICAM1, IRF-1, and Stat 1 itself) and, in the case of ICAM-1, with consequent airway retention of immune cells bearing ICAM-1 counter-receptors $(14,19,20,22)$.
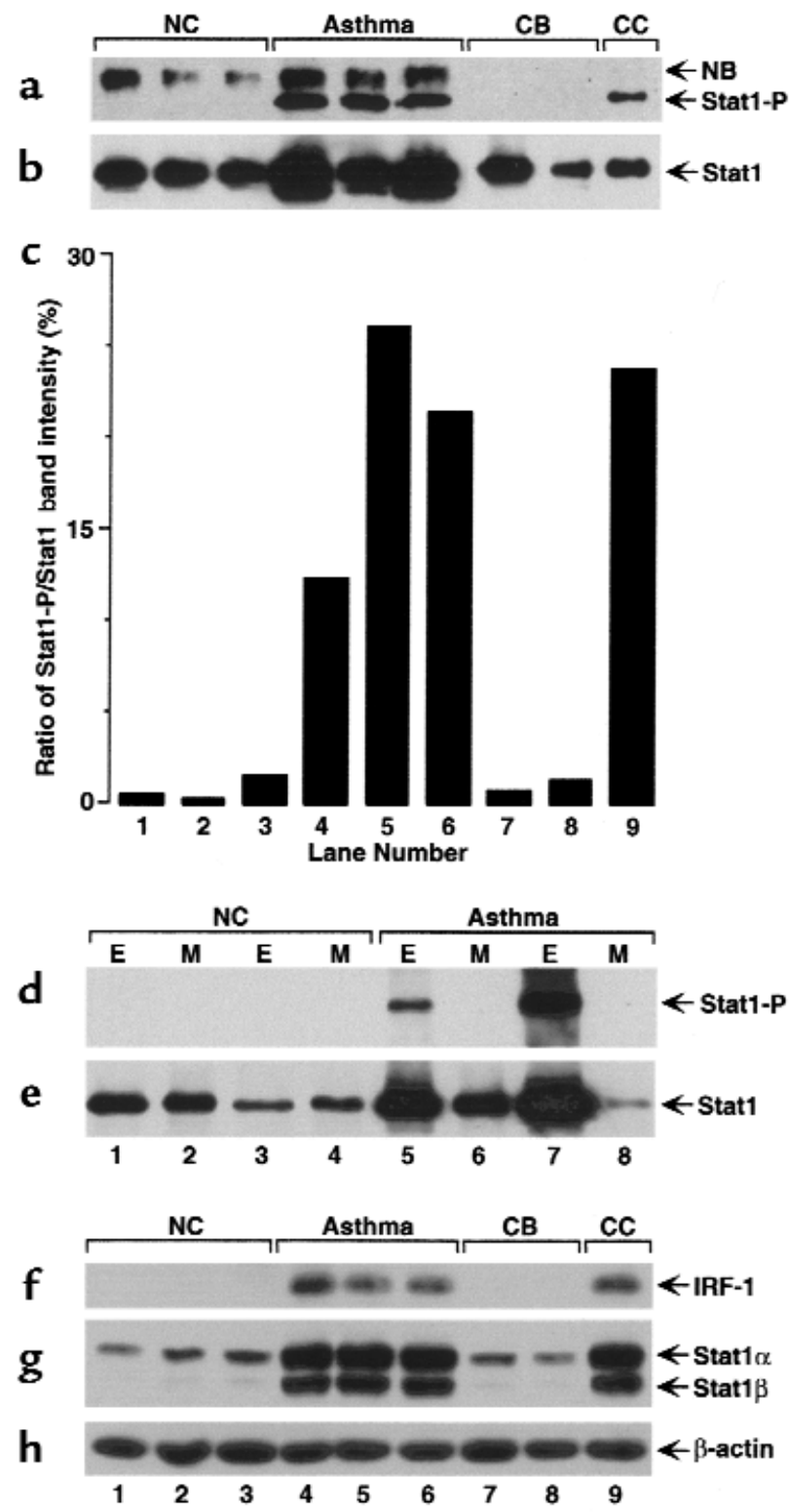

Figure 3

Stat 1 activation in asthma detected by protein phosphorylation. (a) Immunoprecipitation/immunoblot results for phosphorylated Stat1 from 3 control (lanes 1-3), 3 asthmatic (lanes 4-6), and 2 chronic bronchitis (lanes 7 and 8 ) subjects, as well as primary-culture airway epithelial cells stimulated with IFN- $\gamma(100 \mathrm{U} / \mathrm{mL}$ for 24 hours; lane 9). In each case, Stat 1 was immunoprecipitated from epithelial cell lysates and subjected to immunoblotting with anti-phosphotyrosine $\mathrm{mAb}$ conjugated to horseradish peroxidase followed by enhanced chemiluminescence. Arrows indicate positions of a nonspecific band (NB) and phosphorylated Stat1. (b) Results for total Stat1 after membranes were reprobed with anti-Stat $1 \mathrm{mAb}$. Arrows indicate position of Stat1. (c) Ratio of phosphorylated Stat 1 to total Stat 1 band intensity for each condition, based on densitometry of immunoblots in $\mathbf{a}$ and $\mathbf{b}$. Using the same techniques, $\mathbf{d}$ and $\mathbf{e}$ show comparison of airway epithelial (E) and bronchoalveolar macrophage (M) levels of Stat 1 activation in 2 control (lanes 1-4) and 2 asthmatic (lanes 5-8) subjects. Titration of sample amounts to provide equal levels of Stat 1 in each lane still showed no evidence of phosphorylation in samples from nonasthmatic subjects (not shown). ( $f$ and $\mathbf{g}$ ) Immunoblots (without prior immunoprecipitation) of airway epithelial cell lysates for IRF-1 (f), Stat 1 (g) under conditions that separate Stat $1 \alpha$ from Stat $1 \beta$, and control $\beta$-actin (h) 

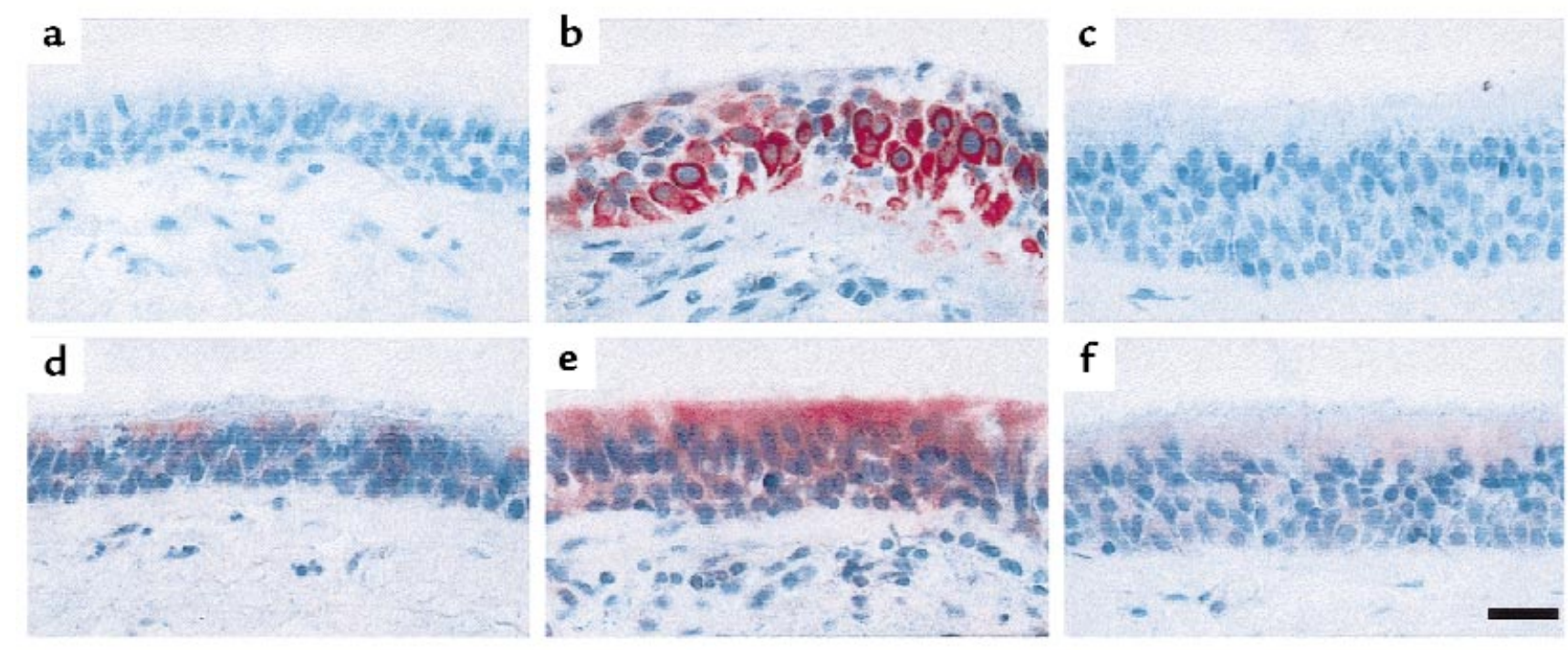

$\mathrm{g}$

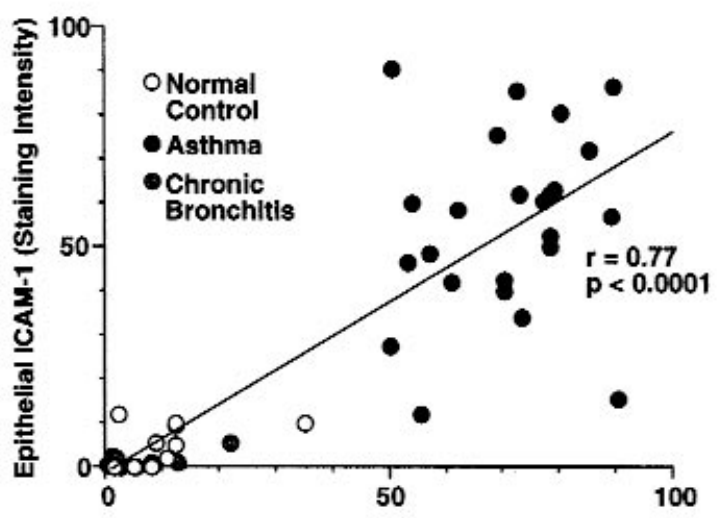

h

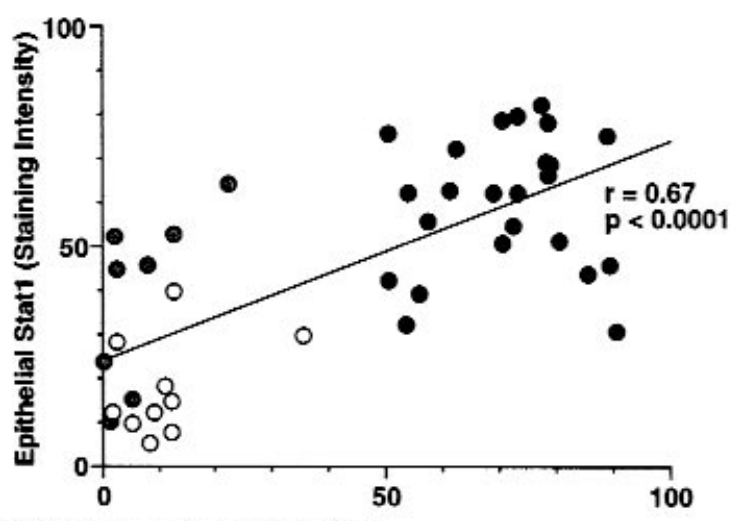

Figure 4

Stat 1 activation correlates with ICAM-1 and Stat 1 expression in airway epithelium. (a-f) Representative photomicrographs of endobronchial biopsy sections from control ( $\mathbf{a}$ and $\mathbf{d}$ ), asthma ( $\mathbf{b}$ and $\mathbf{e}$ ), and chronic bronchitis ( $\mathbf{c}$ and $\mathbf{f}$ ) subjects immunostained with anti-ICAM-1 (a-c) or anti-Stat1 (d-f) mAb. Primary Ab binding was detected using a biotinylated secondary Ab and a streptavidin-alkaline phosphatase complex; tissues were then counterstained with hematoxylin. Control staining with nonimmune IgG gave no detectable signal above background (not shown). Scale bar: $15 \mu \mathrm{M}$. ( $\mathbf{g}$ and $\mathbf{h}$ ) Quantitative analysis of Stat1 activation versus ICAM-1 ( $\mathbf{g})$ and Stat1 $(\mathbf{h})$ immunostaining for all subjects. Values for the percentage of bronchial epithelial cells containing activated (translocated) Stat 1 were determined as described in the legend to Figure 1. Values for ICAM-1 and Stat 1 immunostaining were derived by quantitating the red intensity of epithelial immunostaining using an image analysis system.

Normally low airway levels of IFN- $\gamma$ in asthma. As discussed later here, IFN- $\gamma$ is the only cytokine that we have found to both activate Stat 1 and upregulate ICAM-1 gene expression in airway epithelial cells in vitro and in vivo. Similarly, IFN- $\gamma$ treatment of bronchial epithelial cells brushed from airways of normal controls display increased Stat1 nuclear translocation, and endobronchial biopsies of these subjects exhibit increased Stat 1 translocation and ICAM-1 expression (ref. 14; Figure 2, $\mathrm{c}$ and $\mathrm{f}$; and data not shown). Accordingly, we questioned whether increased levels of IFN- $\gamma$ were responsible for increases in airway epithelial Stat 1 activation and Stat1-dependent gene expression in asthma. However, similar to reports by others $(8,9)$, in situ hybridization experiments indicated no evidence of increased levels of IFN- $\gamma$-expressing immune cells in asthmatic subjects (Figure 5, c and d). We also found no difference in the number of immune cells capable of expressing IFN- $\gamma$, based on in situ hybridization experiments using serial sections from the same biopsies after ex vivo stimulation with PMA and ionomycin (Figure 5, e and f). In addition, airway tissue levels of IFN- $\gamma$ mRNA (in contrast to IL-4) were similarly low in normal control and asthmatic subjects (Figure 5, g and h). As discussed later here, these findings suggest a constitutive abnormality in IFN$\gamma$-dependent signal transduction and gene expression that does not necessarily depend on abnormal production of IFN- $\gamma$ itself.

\section{Discussion}

Constitutive activation of STAT proteins may be found during abnormal proliferation of cells, especially malignant transformation of immune cells, as well as growth arrest and apoptosis (reviewed in ref. 2). In these cases, endogenous protein tyrosine kinase activity of oncoproteins, as well as constitutive activity of cytokine receptors 
or receptor-associated Janus kinases (Jaks), has driven STAT activation. Thus, abnormalities in the Jak-STAT pathway for cytokine signal transduction may be associated with diseases due to abnormal cell growth, but an abnormality in this (or any other) pathway for cytokine signaling has not yet been linked to the development of inflammatory disease.

Our results therefore provide initial evidence for an abnormality in a pathway for cytokine signal transduction (as opposed to altered cytokine production) in the pathogenesis of an inflammatory disease. In particular, we show that the Stat 1 transcription factor is selectively activated in bronchial epithelial cells of asthmatic subjects. The abnormality appears selective because it is not found for other transcription factors (i.e., Stat3, NF-кB, or AP-1) and is not present in other neighboring cell types or in subjects with another form of chronic airway inflammation. In addition, we find that epithelial Stat 1 activity corresponded closely with increased expression of its target genes: ICAM-1, IRF-1, and Stat1. These findings are identical to the profile of Stat 1 activation and Stat1-dependent gene expression triggered by IFN- $\gamma$ signal transduction in isolated human airway epithelial cells and endobronchial explants and in mouse models of airway inflammation (refs. 15-24, and our unpublished results). In all cases, activation of the IFN- $\boldsymbol{\gamma}$-receptor complex leads to Stat 1 phosphorylation, dimerization, nuclear translocation, and consequent binding to genetic targets (typified by the 11-bp inverted repeat in the ICAM-1 gene promoter region) that enhances gene transcription and expression. In the case of asthma, however, Stat 1 activation is detected in the apparent absence of augmented tissue levels of IFN- $\gamma$ (present results, and refs. 8-10). Consequently, asthma appears to exhibit an abnormality in the pathway for cytokine signal transduction that leads to Stat 1 activation and enhanced expression of epithelial ICAM-1, IRF-1, and Stat1 itself. As discussed later here, this pathway for expression of the cell adhesion molecule ICAM-1 (in concert with its chemokine partner, RANTES) may mediate recruitment and activation of immune cells by the airway epithelium $(14,19,20,22)$, whereas autoamplification of Stat 1 action may further predispose asthmatic subjects to excessive airway inflammation and consequent endorgan dysfunction. The role of IRF-1 in causing epithelial gene expression is still uncertain, but expression of inducible nitric oxide synthase (iNOS) in airway epithelial cells appears to be responsive to IFN- $\gamma(32)$, and the characteristics of this response indicate that it may depend (as it does in other cell types) on induction of IRF-1 (33). Given that IFN- $\boldsymbol{\gamma}$-inducible iNOS gene expression can be augmented by IL-4, it appears that the combination of Stat 1 activation (and consequent IRF-1 expression) and IL-4 production may explain increased iNOS gene expression in asthma (34).

Localizing the abnormality in Stat 1 activity to airway epithelial cells is critical to the impact of the present findings. As already noted here, constitutive STAT activities in lymphocytes are associated with malignant transformation, whereas excessive Stat 1 activity in chondrocytes driven by a mutant fibroblast growth factor receptor may be associated with growth arrest (35). Thus,
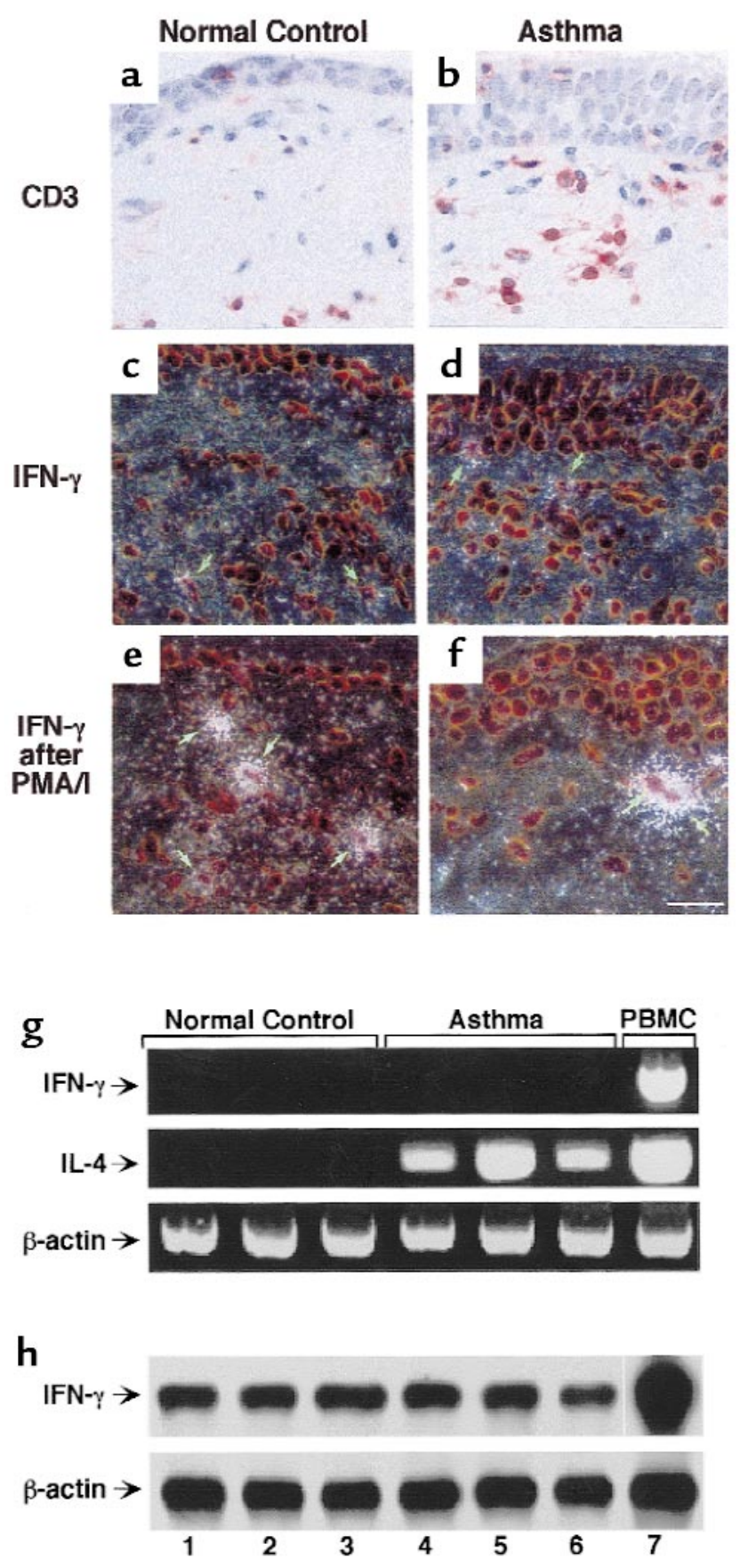

Figure 5

Increased levels of T cells with normal levels of IFN- $\gamma$ expression in asthma. (a-f) Representative photomicrographs of endobronchial biopsy sections from a representative control (a, $\mathbf{d}$, and $\mathbf{e})$ and asthma ( $\mathbf{b}, \mathbf{c}$, and $\mathbf{f})$ subject after immunostaining with anti-CD3 mAb (a and $\mathbf{b}$ ) and after in situ hybridization with ${ }^{35}$ S-labeled IFN- $\gamma$ cRNA using unstimulated (c and $\mathbf{d}$ ) or PMA/ionomycin-stimulated (e and $\mathbf{f}$ ) biopsies. In all cases, hybridization with ${ }^{35}$ S-labeled IFN- $\gamma$ RNA (sense probe) gave no detectable signal above background (not shown). Arrowheads indicate cells expressing IFN$\gamma$ mRNA. Scale bar: $15 \mu \mathrm{M}$. ( $\mathbf{g}$ and $\mathbf{h}$ ) Representative results of RT-PCR from endobronchial tissue (lanes 1-6) and from PMA/ionomycin-stimulated PMBCs (lane 7) using oligonucleotide primers for IFN- $\gamma$, IL-4, and $\beta$ actin. PCR products were subjected to agarose gel electrophoresis and then detected using ethidium bromide staining ( $\mathbf{g}$ ) or subsequent Southern blotting with ${ }^{32} \mathrm{P}$-labeled cDNA probes $(\mathbf{h})$. 
depending on the programmed cytokine response of specific cell types in specific tissues, abnormal Jak-STAT activity may lead to diseases as diverse as lymphoma or dwarfism. Consequently, analysis of cytokine-dependent responses in asthma using sites distant from the airways may not reflect behavior in airway cells. For example, others have indicated that decreased Th1 responses may predispose to asthma, based on an association with diminished delayed-type hypersensitivity reactions to tuberculin (11). However, this association was based on immune responses in the skin and thus does not reflect the specific activity of Th1-driven signaling pathways in airway epithelial cells.

The mechanism that underlies activation of Stat 1 in asthma is uncertain, but several possibilities have been addressed by our work. Thus, we have excluded (as much as possible) overproduction of IFN- $\gamma$ as a basis for activation of epithelial Stat1. As already noted here, our findings extend results by others that IFN- $\gamma$ levels are not increased (and may even be decreased) in asthmatic subjects $(8-10)$. The few reports of IFN- $\gamma$ overproduction in asthma may well reflect the partial overlap between Th1 and Th 2 phenotypes in human $\mathrm{T}$ cells and the likely possibility that both types of cytokines are generated in some asthmatic subjects (reviewed in ref. 12). In the absence of excess IFN- $\gamma$ in asthma, we have screened for other cytokines that might activate Stat 1 and induce ICAM-1 and Stat 1 expression in airway epithelial cells, but we find that, among other known Stat 1 activators $(1,2)$, only IFN- $\alpha / \beta$ is effective in this cell type (15-19, $23)$. However, IFN- $\alpha / \beta$ activates genes by formation of a Stat $1 /$ Stat $2 / \mathrm{p} 48$ complex (1) and so cannot induce ICAM-1 gene expression, which requires a Stat $1 /$ Stat 1 complex (15-18). Furthermore, in the context of the present experiments, we would not expect IFN- $\alpha / \beta$ in the airway epithelium, as viral infection was excluded in our subjects. Similarly, production of IFN- $\alpha / \beta$ (or other cytokines) would not likely cause activation of Stat1 selectively in airway epithelial cells without affecting neighboring cell types. Thus, activation of Stat 1 in asthma may be due to overproduction of cytokine, but current evidence favors an intrinsic abnormality in the epithelial Stat 1 pathway for cytokine signal transduction (analogous to those found during altered cell growth). In that regard, we have further excluded the possibility that asthmatic subjects have the Stat 1 truncation that augments Stat1 phosphorylation (36), as we did not observe the expected change in electrophoretic mobility of this mutant Stat1. More subtle structural alterations in Stat 1 or in proteins that modify its phosphorylation state are under study. However, the cell-specific nature of the Stat 1 abnormality in asthma indicates that an inherited or acquired abnormality is more likely to be found in a regulatory molecule (e.g., kinase or phosphatase) that is expressed or activated selectively in airway epithelial cells or is altered selectively (e.g., by viral infection) $(37,38)$ in epithelial cells.

In conclusion, we provide initial evidence for a fundamental abnormality distinct from those previously invoked in the pathogenesis of asthma. In particular, we find selective activity of epithelial Stat 1 through a pathway that normally responds to production of the Th1 cytokine IFN- $\gamma$. This constitutive Stat 1 signal may lead to overexpression of a subset of epithelial immuneresponse genes, including ICAM-1, Stat1, and IRF-1 transcription factor $(15-18,23)$, and a condition of persistent immune activation. This mechanism for regulating gene expression at the transcriptional level is complemented by regulation at the posttranscriptional level for some epithelial immune-response genes. For example, epithelial RANTES gene expression depends on mRNA stabilization that is inducible directly by respiratory virus (25) and indirectly by virus-triggered IFN- $\gamma$ production (39) or perhaps other endogenous stimuli that exacerbate asthma (14). Similarly, it appears likely that activation and consequent overexpression of Stat1 may predispose asthmatic subjects to excessive airway inflammation in response to any increases in IFN- $\gamma$ production, e.g., during viral infection. In fact, experiments with isolated cells indicate that the level of cellular Stat1 (as well as its activation status) serves to regulate the level of Stat1-dependent gene expression $(23,36)$. Our present findings therefore offer an alternative pathway for airway inflammation in asthma that is based on Th1type cytokine signaling in airway epithelial cells and is distinct from the excessive Th2 cytokine production from immune cells invoked for allergy-driven disease. Interaction between these Th1- and Th2-based pathways may combine to cause an excessive inflammatory response to inhaled stimuli by providing for increased recruitment and retention of immune cells along with the capacity of these cells to respond to allergen.

\section{Acknowledgments}

The authors gratefully acknowledge valuable help from Yael Gris-Alevy, Michelle Jenkerson, Bill Parks, Jill Roby, Bill Roswit, Ken Schechtman, Theresa Tolley, and Nina Zimmerman. This work was supported by grants from the National Institutes of Health and the Alan A. and Edith L. Wolff Charitable Trust.

1. Darnell, J.E., Jr. 1997. STATs and gene regulation. Science. 277:1630-1635. 2. O'Shea, J.J. 1997. Jaks, STATs, cytokine signal transduction, and immunoregulation: are we there yet? Immunity. 7:1-11.

3. Bousquet, J., et al. 1990. Eosinophilic inflammation in asthma. N. Engl. J. Med. 323:1033-1039.

4. Burrows, B., et al. 1989. Association of asthma with serum IgE levels and skin-test reactivity to allergens. N. Engl. J. Med. 320:271-277.

5. Shirakawa, T., et al. 1994. Association between atopy and variants of the $\beta$ subunit of the high-affinity immunoglobulin E receptor. Nat. Genet. 7:125-130.

6. Marsh, D.G., et al. 1994. Linkage analysis of IL4 and other chromosome 5 q31.1 markers and total serum immunoglobulin E concentrations. Science. 264:1152-1156.

7. Hershey, G.K. et al. 1997. The association of atopy with a gain-of-function mutation in the $\alpha$ subunit of the interleukin-4 receptor. N. Engl.J. Med. 337:1720-1725.

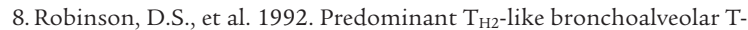
lymphocyte population in atopic asthma. N. Engl. J. Med. 326:298-304.

9. Ying, S., Durham, S.R., Corrigan, C.J., Hamid, Q., and Kay, A.B. 1995. Phenotype of cells expressing mRNA for TH2-type (interleukin 4 and interleukin 5) and TH1-type (interleukin 2 and interferon $\gamma$ ) cytokines in bronchoalveolar lavage and bronchial biopsies from atopic asthmatic and normal control subjects. Am. J. Respir. Cell Mol. Biol. 12:477-487.

10. van der Pouw Kraan, T.C.T.M., et al. 1997. Reduced production of IL-12 and IL-12-dependent IFN- $\gamma$ release in patients with allergic asthma. $J$. Immunol. 158:5560-5565.

11. Shirakawa, T., Enomoto, T., Shimazu, S., and Hopkin, J.M. 1997. The inverse association between tuberculin responses and atopic disorders. Science. 275:77-79.

12. Holtzman, M.J., Sampath, D., Castro, M., Look, D.C., and Jayaraman, S. 1996. The one-two of T helper cells: does interferon- $\gamma$ knockout the Th2 hypothesis for asthma? Am. J. Respir. Cell Mol. Biol. 14:316-318.

13. Holtzman, M.J., et al. 1998. Control of epithelial immune-response genes 
and implications for airway immunity and inflammation. Proc. Assoc. Am. Physicians. 110:1-11.

14. Taguchi, M., et al. 1998. Patterns for RANTES secretion and intercellular adhesion molecule- 1 expression mediate transepithelial $\mathrm{T}$ cell traffic based on analyses in vitro and in vivo. J. Exp. Med. 187:1927-1940.

15. Look, D.C., Pelletier, M.R., and Holtzman, M.J. 1994. Selective interaction of a subset of interferon- $\gamma$ response element binding proteins with the intercellular adhesion molecule-1 (ICAM-1) gene promoter controls the pattern of expression on epithelial cells. J. Biol. Chem. 269:8952-8958.

16. Look, D.C., Pelletier, M.R., Tidwell, R.M., Roswit, W.T., and Holtzman, M.J. 1995. Stat 1 depends on transcriptional synergy with Sp1. J. Biol. Chem. 270:30264-30267.

17. Walter, M.J., Look, D.C., Tidwell, R.M., Roswit, W.T., and Holtzman, M.J. 1997. Targeted inhibition of interferon- $\boldsymbol{\gamma}$-dependent ICAM- 1 expression using dominant-negative Stat1. J. Biol. Chem. 272:28582-28589.

18. Look, D.C., et al. 1998. Direct suppression of Stat 1 function during adenoviral infection. Immunity. 9:871-880.

19. Nakajima, S., et al. 1994. Selective differences in vascular endothelial vs. airway epithelial-T cell adhesion mechanisms. Am. J. Physiol. 267:L422-L432.

20. Nakajima, S., Roswit, W.T., Look, D.C., and Holtzman, M.J. 1995. A hierarchy for integrin expression and adhesiveness among $T$ cell subsets that is linked to TCR gene usage and emphasizes $V \delta 1^{+} \gamma \delta \mathrm{T}$ cell adherence and tissue retention. J. Immunol. 155:1117-1131.

21. Holtzman, M.J., Castro, M., Look, D.C., O’Sullivan, M., and Walter, M.J. 1999. Regulation of epithelial-leukocyte interaction and epithelial immune-response genes. In Asthma and rbinitis. W. Busse and S. Holgate, editors. Blackwell Scientific. Cambridge, MA. In press.

22. Look, D.C., Keller, B.T., Rapp, S.R., and Holtzman, M.J. 1992. Selective induction of intercellular adhesion molecule- 1 by interferon- $\gamma$ in human airway epithelial cells. Am. J. Physiol. 263:L79-L87.

23. Sampath, D., et al. 1998. Autoamplification of Stat1-dependent gene expression. FASEB J. 12:A1390. (Abstr.)

24. Walter, M.J., Kajiwara, N., Sampath, D., Rucker, J., and Holtzman, M.J. 1998. Induction of epithelial immune-response genes in a mouse model of viral bronchitis and hyperreactivity. FASEB J. 12:1453.

25. Koga, T., et al. 1999. Virus-inducible expression of a host chemokine gene relies on replication-linked mRNA stabilization. Proc. Natl. Acad. Sci. USA. In press.
26. Meneely, G.R., Renzetti, A.D., Jr., Steele, J.D., Wyatt, J.P., and Harris, H.W. 1962. Definitions and classification of chronic bronchitis, asthma, and pulmonary emphysema. Am. Rev. Respir. Dis. 85:762-768.

27. Bigby, T.D., and Holtzman, M.J. 1987. Enhanced 5-lipoxygenase activity in pulmonary macrophages compared to monocytes from normal subjects. J. Immunol. 138:1546-1550.

28. Kaptein, A., Paillard, V., and Saunders, M. 1996. Dominant negative Stat3 mutant inhibits interleukin-6-induced Jak-STAT signal transduction. J. Biol. Chem. 271:5961-5964.

29. Broide, D.H., et al. 1992. Cytokines in symptomatic asthma airways. J. Allergy Clin. Immunol. 89:958-967.

30. Demoly, P., et al. 1992. c-fos proto-oncogene expression in bronchial biopsies of asthmatics. Am. J. Respir. Cell Mol. Biol. 7:128-133.

31. Adcock, I.M., Lane, S.J., Brown, C.R., Lee, T.H., and Barnes, P.J. 1995. Abnormal glucocorticoid receptor-activator protein 1 interaction in steroid-resistant asthma. J. Exp. Med. 182:1951-1958.

32. Guo, F.H., et al. 1997. Interferon $\gamma$ and interleukin 4 stimulate prolonged expression of inducible nitric oxide synthase in human airway epithelium through synthesis of soluble mediators. J. Clin. Invest. 100:829-838.

33. Kamijo, R., et al. 1994. Requirement for transcription factor IRF-1 in NO synthase induction in macrophages. Science. 263:1612-1615.

34. Hamid, Q., et al. 1993. Induction of nitric oxide synthase in asthma. Lancet. 342:1510-1513.

35. Su, W.-C.S., et al. 1997. Activation of Stat 1 by mutant fibroblast growthfactor receptor in thanatophoric dysplasia type II dwarfism. Nature. 386:288-292.

36. Shuai, K., Liao, J.Y., and Song, M.M. 1996. Enhancement of antiproliferative activity of gamma interferon by the specific inhibition of tyrosine dephosphorylation of Stat1. Mol. Cell. Biol. 16:4932-4941.

37. Miller, D.M., et al. 1998. Human cytomegalovirus inhibits major histocompatibility complex class II expression by disruption of the Jak/Stat pathway. J. Exp. Med. 187:675-683.

38. Mishkin, J.E., Abrams, C.C., Goatley, L.C., and Dixon, L.K. 1998. A viral mechanism for inhibition of cellular phosphatase calcineurin. Science. 281:562-565.

39. Koga, T., Look, D.C., Tidwell, R.M., and Holtzman, M.J. 1998. Mechanisms for cytokine regulation of $\beta$-chemokine expression in airway epithelial cells. Am. J. Respir. Crit. Care Med. 157:A744. (Abstr.) 